\title{
PERAN DIEGETIC SOUND DALAM MEMBANGUN SUSPENSE PADA FILM “A QUIET PLACE”
}

\author{
Panji Kukuh Priambodho \\ Arif Sulistiyono \\ Lilik Kustanto \\ Jurusan Film \& Televisi, Fakultas Seni Media Rekam, Institut Seni Indonesia Yogyakarta \\ Jl. Parangtritis km. 6.5 Yogyakarta Telp. (0274) 381047
}

\begin{abstract}
ABSTRAK
Film A Quiet Place di sutradarai oleh John Krasinki. Film ini berdurasikan 90 menit dan berdiri di bawah naungan Paramount Picture. Adapun prestasi dari film A Quite Place yakni pada Hollywood Film Award 2018 sebagai pemenang Sound of the Year, dan berbagai prestasi lainnya di bidang suara. Skripsi Pengkajian Seni yang berjudul "Peran Diegetic Sound Dalam Membangun Suspense Pada Film A Quiet Place' ini bertujuan untuk melihat bagaimana diegetic sound berperan dalam pembangunan suspense pada film A Quiet Place.

Penelitian ini merupakan penelitian kualitatif dengan pendekatan deskriptif. Penelitian dilakukan dengan mengobservasi data pada film, menganalisis, memilah dan memperhatikan bagaimana suspense terjadi, lalu setiap titik suspense diamati setiap komponen pembentuk diegetic sound, dan selanjutnya menggabungkan data-data yang berkaitan sehingga didapatkan kesimpulan bagaimana suspense dapat dibangun dengan diegetic sound.

Berdasarkan hasil kajian dapat disimpulkan bahwa Diegetic sound pada film A Quiet Place mampu membangun ketegangan atau suspense. Hal ini dilihat berdasarkan dari hasil analisa bahwa komponen diegetic sound seperti onscreen sound, offscreen sound, external diegetic sound dan internal diegetic sound memiliki perannya masing-masing dalam pembangunan suspense, setiap komponen diegetic sound memiliki motif kemunculan yang berbeda-beda namun tujuan mereka sama-sama sebagai pemancing atau pemantik tensi suspense.
\end{abstract}

Kata Kunci: Film “A Quiet Place”, Diegetic Sound, Suspense

\section{Pendahuluan}

Film dewasa kini dibangun berdasarkan unsur-unsur yang mendukung terbentuknya film tersebut. Unsur-unsur ini melibatkan pencahayaan, tata kamera, suara, naskah, tata rias, busana dan artistik. Semua unsur pada film memiliki peran masing-masing dan saling mendukung satu sama lain untuk membentuk suatu harmoni dan ikatan untuk disajikan ke masyarakat luas sebagai hiburan atau pembelajaran, oleh karena itu para movie maker kini berbondong-bondong untuk menyajikan film yang dapat menarik sekaligus melekat di hati penonton dengan upaya menonjolkan unsur suara pada film tersebut.

Diegetic sound adalah suara dialog, efek suara, serta suara musik atau lagu yang berasal dari dunia cerita filmya, unsur-unsur suara yang nampak maupun tidak nampak tetapi masih memiliki hubungan dengan cerita film bisa dibilang itu merupakan diegetic sound, akan tetapi diegetic sound juga bisa dipengaruhi oleh pembatasan frame. Suara di luar dan dalam frame sangat 
berbeda karakteristiknya dan bisa dimanfaatkan sebagai penunjuk jalannya cerita. Selain suara yang secara fisik tampak dalam frame, suara batin yang dipikirkan dan didengar oleh karakter juga merupakan diegetic sound (Pratista 2017, 208).

Diegetic sound dapat dibagi menjadi onscreen, offscreen sound, external, dan internal diegetic sound dimana masingmasing komponen penyusun diegetic sound tersebut menjelaskan dan mendukung ciriciri bagaimana suatu suara dapat dibilang sebagai diegetic sound.

Penelitian dengan topik "Peran Diegetic Sound dalam Membangun Suspense pada Film A Quiet Place" akan lebih memfokuskan pada meneliti bagaimana diegetic sound dapat membangun suspense dengan mempertimbangkan poin-poin yang berpengaruh dalam terbentuknya film ini.

Film A Quiet Place disutradarai oleh John Krasinki. Film ini berdurasikan 90 menit dan berdiri dibawah naungan Paramount Picture. Film box office 'A Quite Place' telah meraup pemasukkan yang melonjak melewati perkiraan hingga 50,3 juta dolar AS pada pembukaan di 3.508 bioskop. Adapun prestasi dari film A Quite Place ini yakni pada Hollywood Film Award 2018 sebagai pemenang Sound of the Year, pada Hollywood Music In Media Awards (HMMA) 2018 sebagai nominasi Best Original Score - Sci-Fi/Fantasy/Horror Film, pada International Online Cinema
Awards (INOCA) 2018 sebagai pemenang Best Sound Mixing dan Best Sound Editing (IMDb).

Melihat banyaknya prestasi yang diraih film A Quite Place membuat film ini layak sebagai objek penelitian. Penelitian ini difokuskan pada satu titik bidang saja agar analisa yang dilakukan dapat lebih terfokus, salah satu yang diunggulkan pada film $A$ Quite Place adalah pada bidang penataan suaranya pada diegetic sound dimana dibuktikan dengan prestasinya di bidang tersebut.

\section{Pembahasan}

Penelitian ini bertujuan untuk mengidentifikasi bagaimana peran diegetic sound dalam membangun suspense pada film A Quiet Place. Sebelumnya telah dilakukan pengamatan pada film A Quiet Place menggunakan metode observasi untuk memudahkan dalam memilah setiap poinpoin penting berdasarkan setiap sequence, selanjutnya pemilahan akan difokuskan kembali menjadi setiap adegan dengan tujuan mendetailkan pengidentifikasian agar pengamatan dapat dilakukan lebih fokus ke bidang diegetic sound.

$$
\text { Pembahasan pertama akan }
$$
menjelaskan apa saja komponen-komponen suara pada diegetic sound, bagaimana komponen-komponen tersebut disajikan dalam film A Quiet Place, dan dititik mana sajakah komponen ini akan berperan dalam penelitian pada film A Quiet Place. 
Pembahasan kedua akan menjelaskan bagaimana bentuk-bentuk suspense dan dimana sajakah titik munculnya serta mendeskripsikan juga bagaimana diegetic sound beserta komponennya membangun suspense pada film A Quiet Place. Setelah tahap-tahap tersebut dilakukan maka akan didapatkan kesimpulan mengenai bagaimana diegetic sound berperan dalam membangun suspense pada film A Quiet Place.

\section{Komponen Diegetic Sound}

Diegetic sound dapat dikelompokkan menjadi onscreen dan offscreen sound, selain itu diegetic sound juga dapat diidentifikasi menjadi external dan internal diegetic sound, keempat komponen ini memiliki cirinya masing-masing dimana setiap poin memiliki perannya sendiri. Berikut adalah penjelasan secara umum mengenai komponenkomponen diegetic sound pada film A Quiet Place.

\section{a. Onscreen Sound}

Onscreen sound adalah seluruh suara yang dihasilkan pelaku cerita dan obyek yang berada di dalam frame (onscreen). Secara garis besar penggunaan onscreen sound sudah ada sejak diawal adegan sampai diakhir film. Pada film $A$ Quiet Place penggunaan onscreen sound sangat diminimalisir karena kehadiran dari suara tersebut dapat membuat karakter pada film dalam bahaya. Walaupun diminimalisir, penyajian onscreen sound pada film $A$ Quiet Place sendiri sangat mendetil mulai dari suara yang sangat tipis sampai ke suara yang sangat besar, hal ini dikarenakan konsep dari film $A$ Quiet Place sendiri yakni bagaimana penonton bisa tetap akrab dengan jalan cerita film tanpa menyeret mereka kedalam eksperimen tanpa suara pada film A Quiet Place itu sendiri.

b. Offscreen Sound

Offscreen sound merupakan suara yang berasal dari dalam cerita namun penempatannya berada diluar frame, offscreen sound pada umumnya digunakan untuk memberikan efek kejutan dan ketegangan. Dalam film horor, offscreen sound biasa digunakan untuk memancing pelaku cerita untuk bergerak ke sumber suara, seperti suara piano, air kran yang menyala, suara gedor dan ketuk pintu, serta suara pintu atau jendela yang membuka dan menutup. Pada film $A$ Quiet Place, penggunaan diegetic offscreen sound juga bersifat demikian, kemunculannya memberikan tanda bahwa sesuatu telah terjadi dan sesuatu tersebut merupakan salah satu dari apa yang membuat penonton merasa was-was 
dan kaget sehingga mereka menerkanerka adegan apa yang selanjutnya akan terjadi.

\section{c. Internal Diegetic Sound}

\section{Internal diegetic sound} bersifat subyektif, yakni semua suara yang berasal dari pikiran seorang pelaku cerita. Penonton mampu mendengar suara yang sama seperti apa yang didengar oleh seorang tokoh, namun orang lain dalam cerita film tersebut tidak mampu mendengarnya. Penggunaan internal diegetic sound pada film A Quiet Place yakni tidak ada.

\section{d. External Diegetic Sound}

'External diegetic sound bersifat obyektif, yakni semua suara yang bersumber dari pelaku cerita dan semua obyek fisik disekitarnya yang mampu didengar oleh orang lain yang berada disekitarnya. Seluruh suara dalam cerita film umumnya adalah external diegetic sound. Penggunaan external diegetic sound pada film $A$ Quiet Place sangatlah mendominasi, hal ini dikarenakan sound sendiri sebagai penggerak narasi pada film $A$ Quiet Place sendiri. Selain itu, external diegetic sound merupakan elemen penting pada film A Quiet Place karena dengan konsep filmnya sendiri yang lebih mendominankan suara.

\section{Suspense}

Suspense pada film A Quiet Place akan dianalisa berdasarkan keseluruhan film, setelah menganalisa jalannya naratif pada film tersebut maka akan didapatkan bagaimana suspense terjadi dan dibangun pada film A Quite Place. Dalam menganalisa suspense perlu dilakukan analisa naratif dengan menjabarkan setiap plotnya. Penjabaran unsur naratif pada penelitian ini akan dianalisa berdasarkan dengan rentetan sequence dan dilanjutkan dengan menjabarkan scene pada film A Quiet Place, hal ini dilakukan karena pencarian titik suspense tidak selamanya muncul pada film, pemilihan sampel berdasarkan sequence ditujukan agar pengidentifikasian sampel tidak terlalu luas dan poin penting sesuai dengan kebutuhan dapat ditemukan sehingga dapat lebih terfokus dengan variabel penelitian, selain itu dengan mengidentifikasi setiap sequence dan scenenya akan mempermudah dalam menemukan titik suspense. Berikut merupakan salah satu penganalisaan film A Quiet Place pada Sequence 2

Adapun indikator terjadinya suspense menurut teori oleh Brewer dan Lichtenstein yakni sebagai berikut:

Tabel Indikator Suspense 


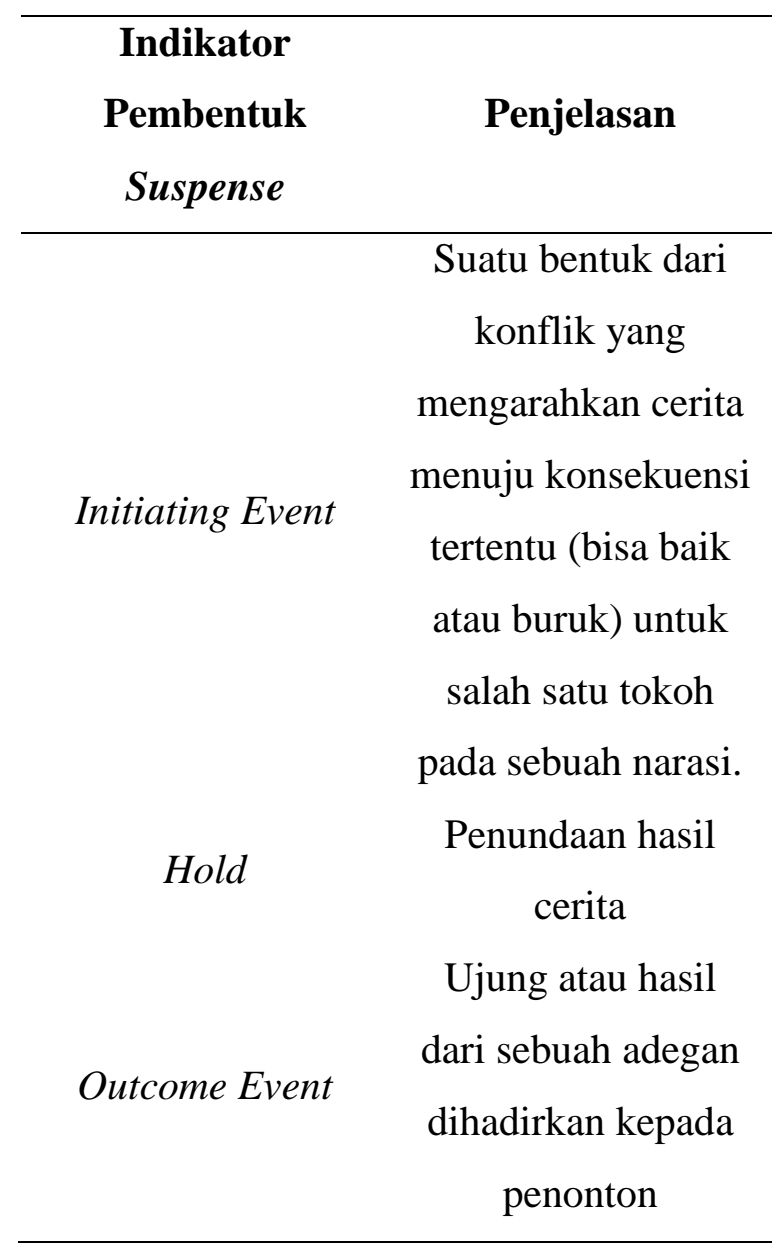

a Analisis Diegetic Sound pada Sequence 2

Suspense dibangun melalui suara lentera yang pecah, dan didukung oleh suara off screen
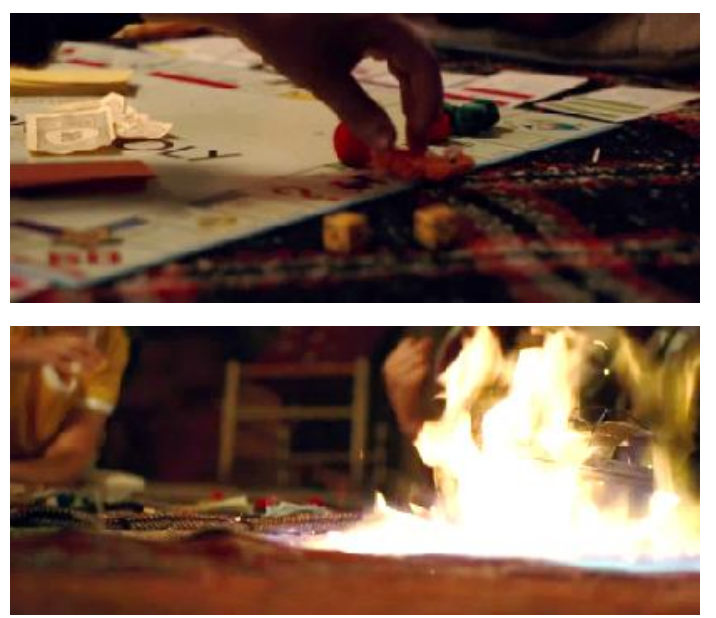
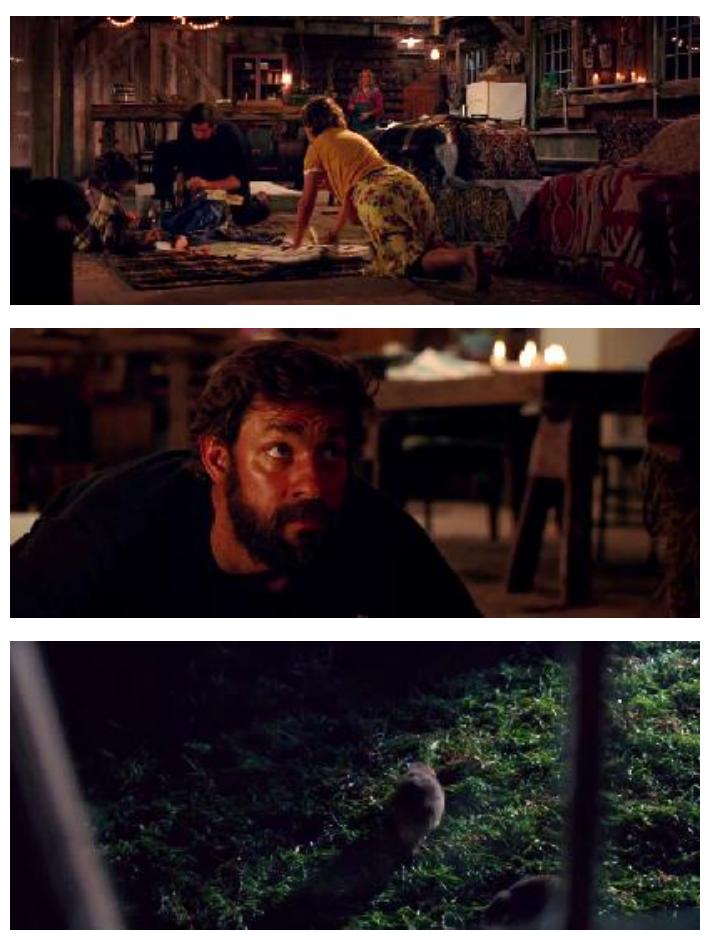

- External Diegetic Sound: Suara mengocok dadu

- Onscreen: Suara mengocok dadu

- External Diegetic Sound: Suara lentera kaca yang tersenggol dan pecah, suara api yang berkobar

- Onscreen: Suara lentera kaca yang tersenggol dan pecah, suara api yang berkobar

- External Diegetic Sound: Suara ayah memadamkan api

- Onscreen: Suara ayah memadamkan api

- Offscreen: Suara kepakan sayap kumpulan burung

- Offscreen: Suara hantaman keras pada benda seng

- External Diegetic Sound: Suara rakun yang jatuh

- Onscreen: Suara rakun yang jatuh 
Hasil analisa pada sequence 2 menjelaskan bahwa diegetic sound pada sequence ini membangun suspense secara perlahan, initiating event terjadi melalui suara lampion yang pecah. Didukung dengan scene yang pelan dan halus serta adegan yang di hold, diegetic sound kembali dimunculkan dengan memberikan offscreen diegetic sound kepakan sayap dan suara burung-burung yang menjelaskan akan kedatangan sesuatu yang tidak disukai oleh sekumpulan burung tersebut. Selanjutnya hold kembali dihadirkan di gambarkan dengan keluarga Abbott yang lega, selanjutnya initiating event kembali dihadirkan dengan munculnya offscreen diegetic sound hantaman keras pada atap rumah mereka. Pengembangan suspense terus meningkat dan diselesaikan dengan outcome event dimana terlihat bahwa suara gaduh tersebut disebabkan oleh dua ekor rakun.

\section{Kesimpulan}

Berdasarkan hasil penelitian mengenai peran Diegetic Sound dalam membangun Suspense pada film A Quiet Place didapatkan kesimpulan yakni:

Berdasarkan hasil penelitian mengenai peran Diegetic Sound dalam membangun Suspense pada film A Quiet Place didapatkan kesimpulan berdasarkan rumusan masalah yakni:

1. Diegetic sound pada film A Quiet Place dibangun berdasarkan komponenkomponen suara, mereka antara lain, onscreen sound, offscreen sound, external diegetic sound dan internal diegetic sound.

2. Berdasarkan dari hasil penelitian yang dilakukan serta analisis dan observasi dari film A Quiet Place, dari seluruh komponen diegetic sound yang dianalisis serta diamati, komponen diegetic sound yang memiliki pengaruh penting dalam membangun suspense pada film ini adalah onscreen sound dan external diegetic sound. Karena kedua unsur ini memiliki porsi kemunculan yang lebih dominan dibandingkan komponen yang lain dan kemunculannya di setiap adegan memiliki faktor pembangun suspense pada film ini. Adapun komponen lainnya pada diegetic sound yakni offscreen sound yang perannya juga sebagai pemberi tanda baik dalam initiating event maupun memberi kesan hold namun kemunculannya tidaklah banyak pada film A Quiet Place dan untuk internal diegetic sound tidak dapat ditemukan penggunaannya pada film A Quiet Place.

3. Sifat diegetic sound dalam membangun suspense pada film A Quiet Place di sini yaitu membangun secara bertahap yang dalam artian setiap diegetic sound yang dihasilkan akan memberikan hambatan atau initiative event baru pada tokoh dan hambatan di sinilah yang memberikan unsur suspense dimana penonton akan 
dibawa dalam rasa cemas serta was-was mengenai bagaimana tokoh dalam film akan melewati hambatan tersebut.

4. Tidak semua unsur suspense pada film $A$ Quiet Place dibangun menggunakan diegetic sound melainkan unsur pengadeganan juga mengambil peran pada jalannya cerita film ini.

5. Berdasarkan hasil penjabaran setiap sequence yang memiliki titik suspense, suspense pada film A Quiet Place memiliki pola yang sama dalam mengembangkan pembentukan suspense nya yakni setiap suspense akan ditingkatkan melalui sebuah initiating event dan hambatan pada tokohnya, selain itu penundaan cerita atau hold juga akan terus diberikan sampai pada tingkat titik tertinggi suspense dan setelah itu suspense diakhiri dengan outcome event yang merupakan hasil atau resolusi dari suspense tersebut.

6. Jika suara pada film A Quiet Place tidak membangun apapun maka hambatan yang diberikan kepada tokoh dalam cerita tidak akan terjadi sehingga konflik dalam film inipun tidak akan terjadi.

\section{Daftar Pustaka}

Brewer, W.F. dan E.H. Lichtenstein. Event schemas, story schemas, and story grammars. In: J. Long and A. Baddeley (eds.), Attention and performance, vol. 9, 363-379. Hillsdale, NJ: Erlbaum, 1981.
Brewer, W.F. dan E.H. Lichtenstein. Stories are to Eentertain: A Structural-Affect Theory Of Stories. University of Illinois at Urbana: Champaign, 1982.

Biran, Misbach Yusa. Teknik Menulis Skenario Film Cerita. Jakarta: Pustaka Jaya, 2009.

Biran, Misbach Yusa. Sejarah Film 19001950: Bikin Film di Jawa. Jakarta: Komunitas Bambu, 2009.

Bordwell, David, dan Kristin Thompson. Film Art: An Introduction, Eighth Edition. New York: McGraw-Hill, 2008.

Eriyanto. Analisis Naratif: Dasar-dasar dan Penerapannya dalam Analisis Teks Berita Media. Jakarta: Kencana, 2013.

Kintsch, W. Learning from text, levels of comprehension, or: Why anyone would read a story anyway?. Poetics 9. 1980.

Lacey, Nick. Narrative and Genre: Key Concepts in Media Studies. London: Maemillan, 2000.

Lutters, Elizabeth. Kunci Sukses Menulis Skenario. Jakarta: Grasindo, 2014.

McQuail, Denis. The Sage Handbook of Nedia Studies. Thousand Oaks: Sage Publication, 2004.

Moleong, Lexy J. 2013. Metode Penelitian Kualitatif Edisi Revisi. Bandung : PT. Remaja Rosdakarya.

Pratista, Himawan. Memahami Film Edisi 2. Yogyakarta: Montase Press, 2017.

Sugiyono. Metode Penelitian Pendidikan Pendekatan Kuantitatif, Kualitatif, dan $R \& D$. Bandung: Alfabeta, 2010.

Truffaut, François: "Hitchcock om Hitchcock" (Hitchcock about Hitchcock). Denmark, 1973. Rhodos. ISBN: 87-74-96-369-4.

\section{Jurnal Online}

Hoeken, Hans. Mario van Vliet. Suspense, curiosity, and surprise: How discourse structure influences the affective and cognitive processing of a story. Journal of Poetics 26 (2000) 277-286. (Diakses pada tanggal 3 Juni 2019). www.elsevier.nl/locate/poetic 